\title{
IMPACT ASSESSMENT OF A MINE SUBSIDENCE ON NATIVE VEGETATION OF SOUTH EASTERN COALFIELDS, INDIA
}

\author{
Ashish Kumar Vishwakarma ${ }^{1,}$, Ashwani Kumar Agnihotri ${ }^{1}$, Rajesh Rai $^{1}$, B. K. Shrivastva ${ }^{1}$, Sachin Mishra $^{1}$ \\ ${ }^{1}$ Department of Mining Engineering, Indian Institute of Technology, Varanasi, India - a.was.v795@ gmail.com, \\ ashwanika.rs.civ15@itbhu.ac.in, rajeshkumarrai@rediffmail.com, (bkshrivastva.min,smishra.rs.apc13)@itbhu.ac.in
}

Commission V, SS: Disaster Monitoring, Damage Assessment and Risk Reduction

KEY WORDS: Mining, Subsidence, Vegetation, Remote Sensing, NDVI

\begin{abstract}
This study aims to evaluate the effect of underground coal mining subsidence on the growth of native vegetation. For this study, an underground coal mine of South Eastern Coalfields Limited (SECL), India was selected. Changes in vegetation indices were analyzed using three remote sensing data of the previous five years. Three period's Landsat 8 OLI resolution image data were used to calculate Normalized Difference Vegetation Index (NDVI) of the years 2014, 2016 and 2018 in QGIS environment. The study showed that the local grassland and forest were affected by the mining exploitation and subsidence but those effects were not significant to have an adverse impact on the same. The short-term mining was having an impact on the vegetation growth but the effects gradually disappeared with the gradual stabilization of the subsided land and in absence of human interference, vegetation recovered well. In long-term, subsidence was not having a major impact on the vegetation growth. Thus, coal resources exploitation and subsidence of the said mine of SECL did not bring out an adverse impact on a wide range of forest and grassland ecosystems, and these ecosystems could carry the partial destruction and ultimately stabilized ecosystems by self-repair.
\end{abstract}

\section{INTRODUCTION}

Mining plays an important role in productions of raw materials, minerals and coal to be used for industrial and domestic needs (Brunn et al., 2001, Dittmann et al., 2002). The fuel supply and energy creation have a major dependency on the mining industry (Brunn et al., 2001) due to which it has a vital role in the wellbeing of regional to global economies. There are various impacts of mining on its surroundings which may lead to a number of geological changes such as collision with mining cavities, ground movements and deformations of aquifers which ultimately leading to mining subsidence. An irreversible damage to soil cohesion may occur due to usage of heavy machines in coal extraction processes from mine galleries and eventually, compression of soil substrates may take place (Brunn et al., 2002, Eikhoff et al., 2007). Several adverse environmental impacts of mining subsidence might be also produced such as soil erosion, soil and water contamination, flooding due to damages to aquifers and inundation at the surface, as well as damages to the infrastructures. These all have a cumulative impact on the growth and health of the native vegetation. Changes in the health of vegetation may also act as vital markers for evaluating the land changes in a functioning and reclaimed mining region (Jat et al., 2008, Zuo et al., 2014). Geographic Information Systems (GIS) and Remote Sensing (RS) techniques have shown clear advantage over conventional field inspection and lab estimations for evaluating long to short-term landscape dynamics (Venkatesan and Padmanaban, 2012, Rajchandar et al., 2017), particularly for bigger areas, where ground leveling and surveying by Global Positioning System (GPS) are expensive, labor-intensive and time-consuming, GIS and RS offer quick and effective information on geological variations and subsidence (Morfeld et al., 2002).
This study aims to evaluate the effect of underground coal mining subsidence on the growth of native vegetation through the analyses of short-term i.e. five year's landscape dynamics using RS and GIS techniques.

\section{MATERIALS AND METHODS}

\subsection{Study site}

The study area is located in Anuppur district of Madhya Pradesh, India at the longitude $81^{\circ} 57^{\prime} 55^{\prime \prime}$ and latitude $23^{\circ} 11^{\prime} 17^{\prime \prime}$ (Fig. 1). Area falls under SOI toposheet no. 64E/16 and 64I/4 and comes under north-west section of SECL coalfields region. Anuppur - Chirimiri section of SECL railway passes through it.

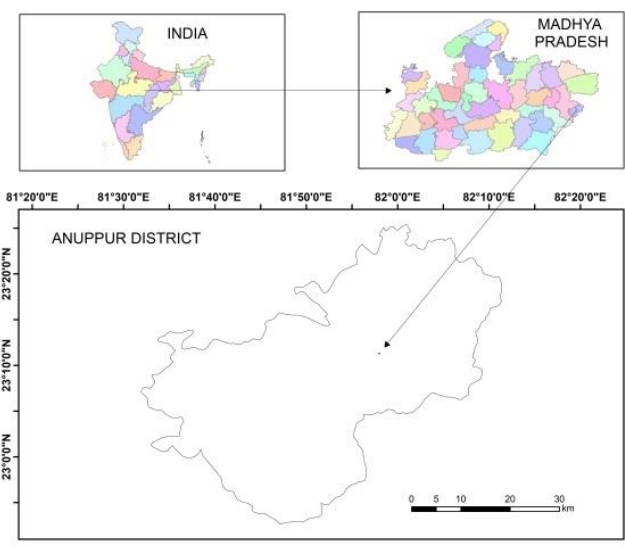

Fig 1: Location map of the study area

* Corresponding author 


\subsection{Satellite data}

Three LANDSAT 8 OLI imageries, covering years 2014-2018 with 30m spatial resolution (Visalatchi and Padmanaban, 2012, Padmanaban and Sudalaimuthu, 2012, Padmanaban, 2012, Padmanaban, and Kumar, 2012) were used for the analysis. To be consistent with seasonal variations and vegetation health, seasons with very less or zero rainfall were considered for the study and images with zero cloud cover at area of interest were downloaded from United States Geological Survey (USGS) gateway (Padmanaban, 2012, Padmanaban, and Kumar, 2012). The selected month for image download was May of 2014, 2016 and 2018 .

\subsection{Image Processing}

Topographical map and satellite data sources were used for this study. LANDSAT 8 OLI data of 143 paths and 44 rows of the study area were downloads from USGS website. The image processing was done in one of the very popular open source software called QGIS. NDVI was calculated in QGIS environment. Five classes were made for NDVI images of the study area. The temporal change of NDVI was done for the same area with different years.

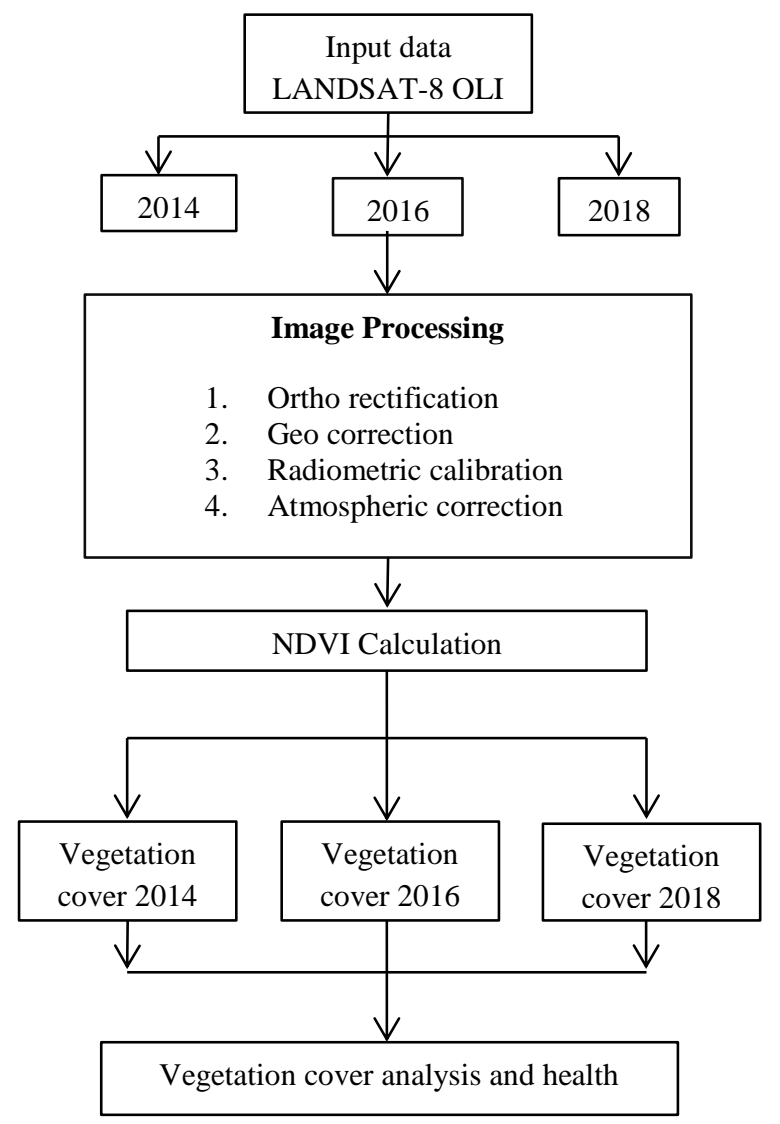

Fig. 2: Methodology for the analysis of vegetation health (NDVI)

\subsection{Vegetation health and coverage}

NDVI calculation was done using formula (Goslee, 2011, Streiner, 1993, Bivand et al., 2008):
$\mathrm{NDVI}=(\mathrm{NIR}-\mathrm{Red}) /(\mathrm{NIR}+\mathrm{Red})$

Where, $\quad$ NIR $=$ Near Infrared Band value,

$\mathrm{R}=$ Red Band value recorded by the Landsat 8 OLI imageries

The NDVI value ranges from -1 to +1 (Walston et al., 2009, Dubovyk et al., 2013). Higher value of NDVI shows a highly productive healthy vegetation i.e. NDVI value for forest ranges from 0.6 to 0.8 (Assal et al., 2014) while lower value shows lowly productive vegetation for example, shrub and grassland shows NDVI value of 0.2-0.3 (Meza Diaz and Blackburn, 2003, Bhowmik and Cabral, 2013). The value closer to -1 represents damaged vegetation (e.g. usually water) whereas, less than 0.1 represents a degraded vegetation (e.g. barren areas such as sand, rock and snow). In this study NDVI value ranged from $0.19-0.27$ hence, the area of interest was found to be covered with shrubs and grasslands. Based on the comparative values of NDVI in this category, vegetation with higher NDVI values was named as healthy vegetation while vegetation with lower NDVI values was named as unhealthy and damaged vegetation. The obtained NDVI values were classified into five raster zones based on natural breaks. Changes in the area coverage of each raster zones during five years were calculated and dynamics in vegetation health and coverage were quantified.

\section{RESULTS AND DISCUSSION}

A decrease in area coverage of vegetation with higher NDVI value (healthy vegetation) was observed during 2014 - 2016. It was associated with an increase in the area coverage of vegetation with lower values of NDVI (unhealthy vegetation). Highest decrease in NDVI values was in between 2014 to 2016, i.e. the mean NDVI values reduced from 0.27 to 0.24 (Fig. 3, Table 1). The healthy vegetation was decreased from $48.86 \%$ to $28.41 \%$ with an annual rate of $6.82 \%$ while the damaged and unhealthy vegetation was increased from 51.14 to 71.59 with an annual rate of $10.23 \%$ (Table 1). Thus, due to mining subsidence, an overall increase in damaged and unhealthy vegetation was seen during $2014-2016$.

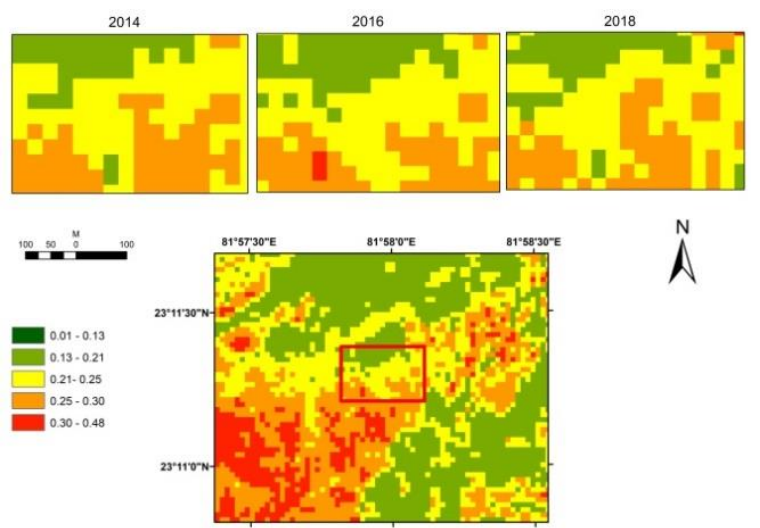

Fig. 3: NDVI map of the damaged area in May 2014, 2016 and 2018

During 2016 - 2018, a substantial increase in area coverage of healthy vegetation was seen whereas, the area coverage of damaged and unhealthy vegetation had shown a decreasing tendency. The healthy vegetation was increased by $38.64 \%$ while the damaged and unhealthy by $18.18 \%$. 
The change in NDVI values directly reflects the change in the greenness of the area under consideration. The changes may be due to various factors, like change in soil physical structures which includes the texture related components viz. sand, silt and clay. These textures unite in different ratio to form various types of soils which suits for a specific range of plants.

The subsidence resulted into deformation of the affected land and subsequently a change in the texture composition (Tripathi et al., 2009). As discussed earlier, due to this, a change in the suitability of textures takes place which resulted into an imbalance and improper supply of various soil available nutrients to the plants, ultimately affecting the major physiological processes of the plants like photosynthesis, chlorophyll synthesis, etc. and thus consequently impaired chlorophyll synthesis resulted into the discoloration of the leaves. Chlorophyll imparts green color to the plants and as NDVI measures the greenness, its values decreases abruptly due to damages in native vegetation.

Table 1: Vegetation health changes between $2014-2016$ and $2016-2018$

\begin{tabular}{|l|l|c|l|c|}
\hline \multirow{2}{*}{$\begin{array}{l}\text { NDVI } \\
\text { Values }\end{array}$} & \multicolumn{2}{|c|}{$\begin{array}{c}\text { Vegetation area } \\
\text { change from 2014 to }\end{array}$} & \multicolumn{2}{c|}{$\begin{array}{c}\text { Vegetation area } \\
\text { change from 2016 to }\end{array}$} \\
\cline { 2 - 5 } & \multicolumn{2}{|c|}{$(\%)$} & $\left(\mathrm{m}^{2}\right)$ & \multicolumn{2}{c|}{$(\%)$} & $\left(\mathrm{m}^{2}\right)$ \\
\hline $\begin{array}{l}0.25- \\
0.27\end{array}$ & $\begin{array}{l}\text { Decreased } \\
\text { by 50\% }\end{array}$ & 9000 & $\begin{array}{l}\text { Increased by } \\
340 \%\end{array}$ & 30600 \\
\hline $\begin{array}{l}0.24- \\
0.25\end{array}$ & $\begin{array}{l}\text { Decreased } \\
\text { by 34.78 \% }\end{array}$ & 7200 & No change & 0 \\
\hline $\begin{array}{l}0.22- \\
0.24\end{array}$ & $\begin{array}{l}\text { Increased by } \\
23.52\end{array}$ & 3600 & $\begin{array}{l}\text { Decreased } \\
\text { by 28.57 }\end{array}$ & 5400 \\
\hline $\begin{array}{l}0.20- \\
0.22\end{array}$ & $\begin{array}{l}\text { Increased by } \\
100 \%\end{array}$ & 10800 & $\begin{array}{l}\text { Decreased } \\
\text { by 45.83 \% }\end{array}$ & 9900 \\
\hline $\begin{array}{l}0.19- \\
0.20\end{array}$ & $\begin{array}{l}\text { Increased by } \\
12.5 \%\end{array}$ & 1800 & $\begin{array}{l}\text { Decreased } \\
\text { by 94.44 \% }\end{array}$ & 15300 \\
\hline
\end{tabular}

\section{CONCLUSIONS}

By above analysis of vegetation index changes of previous five years from three time's imagery, it can be seen that from 2014 to 2016 , almost entire vegetation indices indicated a declining trend and from 2016 to 2018 , the vegetation index had tended to increase. This proposes that at the initial stage of mining subsidence, damages to surface structures may had a negative impact on the vegetation growth, but due to gradual stabilization of the subsided land, adequate rainfall and absence of human interference in the region, the growth had resumed. Thus subsidence impact on the growth of vegetation had decreased to a major extent with time.

\section{REFERENCES}

Assal, T. J.; Sibold, J.; Reich, R. Modeling a Historical Mountain Pine Beetle Outbreak Using Landsat MSS and Multiple Lines of Evidence. Remote Sens. Environ. 2014, 155, 275-288.

Bhowmik, A. K.; Cabral, P. Cyclone Sidr Impacts on the Sundarbans Floristic Diversity. Earth Sci. Res. 2013, 2, 62-79. Brunn, A.; Busch, W.; Dittmann, C.; Fischer, C.; Vosen, P. Monitoring Mining Induced Plant Alteration and Change
Detection in a German Coal Mining Area using Airborne Hyperspectral Imagery. 2002.

Brunn, A.; Dittmann, C.; Fischer, C.; Richter, R. Atmospheric correction of 2000 HyMAP data in the framework of the EUproject MINEO. In Proceedings of SPIE; 2001; Vol. Volume 454 , pp. 382- 392 .

Dittmann, C.; Vosen, P.; Brunn, A. MINEO (Central Europe) environment test site in Germany - Contamination/impact mapping and modelling - Final report; 2002.

Dubovyk, O.; Menz, G.; Conrad, C.; Kan, E.; Machwitz, M.; Khamzina, A. Spatio-temporal analyses of cropland degradation in the irrigated lowlands of Uzbekistan using remote-sensing and logistic regression modeling. Environ. Monit. Assess. 2013, 185, 4775-4790.

Eikhoff, J. Developments in the German coal mining industry. Entwicklungen im Deutsch. Steinkohlenbergbau 2007, 143, 10$16+4$.

Jat, M. K.; Garg, P. K.; Khare, D. Monitoring and modelling of urban sprawl using remote sensing and GIS techniques. Int. J. Appl. Earth Obs. Geoinf. 2008, 10, 26-43.

Meza Diaz, B.; Blackburn, G. A. Remote sensing of mangrove biophysical properties: evidence from a laboratory simulation of the possible effects of background variation on spectral vegetation indices. Int. J. Remote Sens. 2003.

Morfeld, P.; Ambrosy, J.; Bengtsson, U.; Bicker, H.; Kalkowsky, B.; Ksters, A.; Lenaerts, H.; Ruther, M.; Vautrin, H. J.; Piekarski, C. The risk of developing coal workers' pneumoconiosis in german coal mining under modern mining conditions. Ann. Occup. Hyg. 2002, 46, 251-253.

Padmanaban, R. Integrating of Urban Growth Modelling and Utility Management System using Spatio Temporal Data Mining. Int. J. Adv. Earth Sci. Eng. 2012, 1, 13-15.

Padmanaban, R.; Kumar, R. Mapping and Analysis of Marine Pollution in Tuticorin Coastal Area Using Remote Sensing and GIS. Int. J. Adv. Remote Sens. GIS 2012, 1, 34-48.

Padmanaban, R.; Sudalaimuthu, K. Marine Fishery Information System and Aquaculture Site Selection Using Remote Sensing and GIS. Int. J. Adv. Remote Sens. GIS 2012, 1, pp 20-33.

Rajchandar, P.; Bhowmik, A. K.; Cabral, P.; Zamyatin, A.; Almegdadi, O.; Wang, S. Modelling Urban Sprawl Using Remotely Sensed Data: A Case Study of Chennai City, Tamilnadu. Entropy 2017, 19, 163.

Tripathi, N., Singh, R.S., and Singh, J.S. Impact of post-mining subsidence on nitrogen transformation in southern tropical dry deciduous forest, India. Environ. Res. 2009, 109:258-266

Venkatesan G; Padmanaban, R. Possibility Studies and Parameter Finding for Interlinking of Thamirabarani and Vaigai Rivers in Tamil Nadu, India. Int. J. Adv. Earth Sci. Eng. 2012, 1, 16-26.

Visalatchi; Padmanaban, R. Land Use and Land Cover Mapping and Shore Line Changes Studies in Tuticorin Coastal Area Using Remote Sensing. Int. J. Remote Sens. 2012, 1, 112 . 
The International Archives of the Photogrammetry, Remote Sensing and Spatial Information Sciences, Volume XLII-5, 2018 ISPRS TC V Mid-term Symposium “Geospatial Technology - Pixel to People”, 20-23 November 2018, Dehradun, India

Walston, L. J.; Cantwell, B. L.; Krummel, J. R. Quantifying spatiotemporal changes in a sagebrush ecosystem in relation to energy development. Ecography (Cop.). 2009, 32, 943-952.

Zuo, C.; Ma, F.; Hou, J. Representatives of mining subsidence analysis visualization of China. Liaoning Gongcheng Jishu Daxue Xuebao (Ziran Kexue Ban)/Journal Liaoning Tech. Univ. (Natural Sci. Ed. 2014, 33, 788-792. 